\title{
Design and development of RF power detector for microwave application
}

\author{
Mohamoud Mouse Ali ${ }^{1}$, Siti Zuraidah Ibrahim², Ismahayati Adam ${ }^{3}$, Nurehansafwanah Khalid \\ ${ }^{1,3}$ School of Computer and Communication Engineering, Universiti Malaysia Perlis, Malaysia \\ ${ }^{2,4}$ Advanced Communication Engineering (ACE) Centre, Universiti Malaysia Perlis, Malaysia
}

\begin{tabular}{ll} 
Article Info & ABSTRACT \\
\cline { 1 - 2 } Article history: & $\begin{array}{l}\text { This paper presents the design and development of the RF power detector for } \\
\text { microwave applications that is operating at 2.4GHz using microstrip. The } \\
\text { design of diode detector circuit is simulated using Keysight ADS software tool. }\end{array}$ \\
$\begin{array}{l}\text { Received Sep 12, } 2018 \\
\text { Accepted Nov 28, } 2018\end{array}$ & $\begin{array}{l}\text { The design of the diode detector includes the matching network, Schottky } \\
\text { diode and the low pass filter. The paper also presents the fabrication and } \\
\text { measurement of the designed circuit. }\end{array}$ \\
\hline
\end{tabular}

\section{Keywords:}

Peak diode detector

RF power detector

Schottky diode

\section{Corresponding Author:}

Siti Zuraidah Ibrahim,

Advanced Communication Engineering (ACE) Centre,

School of Computer and Communication Engineering, Universiti Malaysia Perlis,

Pauh Main Campus, 02600 Arau, Perlis, Malaysia.

Email: sitizuraidah@unimap.edu.my

\section{INTRODUCTION}

$\mathrm{RF}$ power detector is a device which changes the sinusoidal RF signal into a DC voltage for the purpose of measuring the power level of a signal. Diode detectors are a widely used technique for measuring RF power [1]. Diode detectors use the rectification function to change the sinusoidal signal into DC voltage. The significant factor in the design and performance of a circuit or system that works at RF or microwave frequencies is their output power. To understand the basic circuit element up to overall system performance it's crucial to measure the signal level [2-5]. This means that the techniques and power measurement equipment must be precise and suitable. The components in a system must receive the correct signal level from the preceding component and pass the suitable signal level to the next component. In the event that the output signal turns out to be too low, the signal cannot be detected and becomes obscured in noise. On the contrary, if the signal level turns out to be too high, the performance gets to be nonlinear and distortion can result [6].

Diodes allow the voltage to pass only in one direction and blocks in the other direction. Diodes are being used for the RF and microwave power measurement since long time ago but were only limited to lower frequencies [7].

Diode detectors utilize high-frequency diodes to detect the RF power. The diode performs process called rectification, and it converts the RF signal into DC so that the power can be measured. One or more diodes can be used to perform the rectification and makes it resistant to harmonic distortion. Diode detectors typically have large dynamic range usually between -70 to $+20 \mathrm{dBm}$. However, the operation of the diode is not linear, and it is not the same in the entire dynamic range.

RF detectors are used in many applications. They are mainly used for transmitter output power measurement and control. In [2], a wideband diode detector was presented. The design has a bias current which 
can make the design complex, but in this paper, the bias network is removed which made the design simple. Figure 1 shows the diode detector block diagram and Figure 2 shows the diode detector region.

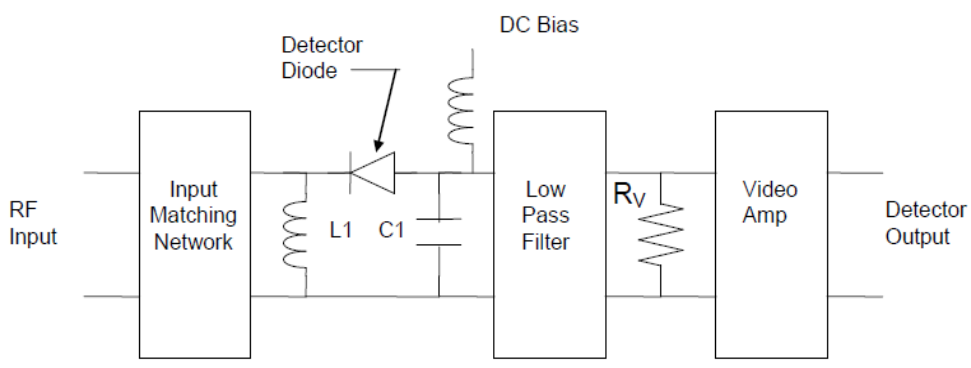

Figure 1. Diode detector block diagram

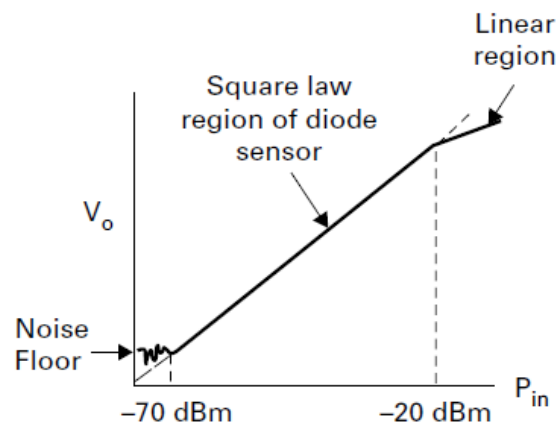

Figure 2. Diode detector regions [7]

\section{RF POWER DETECTOR CIRCUIT DESIGN}

The design of RF power detector in ADS is divided into three parts; the Schottky diode, low pass filter, and matching network. Figure 3 shows the block diagram of the simulated circuit detector in ADS.

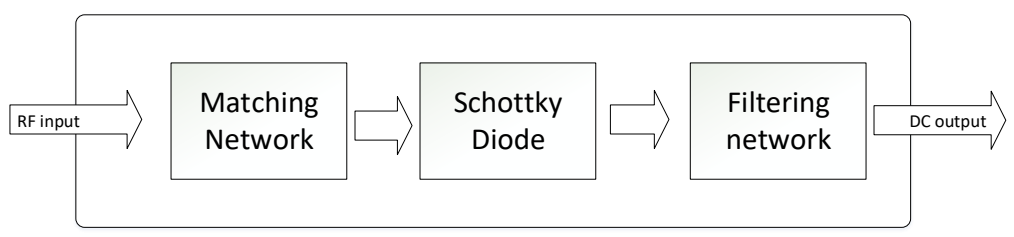

Figure 3. System Block Diagram

The detector is designed using microstrip technique on FR4 substrate. Matching network consists of single open stub matching and filtering network consists of a $100 \mathrm{pF}$ capacitor and $100 \mathrm{k} \Omega$ resistor connected in series. Table 1 shows the substrate specifications. In this paper, the Schottky diode used is HSMS2850, manufactured by HP. The designed circuit is operating at $2.4 \mathrm{GHz}$ because most of the applications are operating at this frequency.

Table 1. Substrate specification

\begin{tabular}{ccr}
\hline Symbols & Descriptions & Value \\
\hline$h$ & Substrate Height & $1.6 \mathrm{~mm}$ \\
$\varepsilon_{r}$ & Dielectric Constant & 4.7 \\
TanD & Dissipation Factor & 0.018 \\
$t$ & Conductor Thickness & $0.017 \mathrm{~mm}$ \\
\hline
\end{tabular}




\subsection{Matching network}

The matching network is one of the most vital part in the design of the diode detector. The main purpose of the matching network is to match the source impedance to that of the detector. The source impedance for most communication applications is $50 \Omega$. The matching network is required because of two main reasons, the first being to provide maximum power transfer and the second being to prevent standing waves formed because of reflection.

There are many ways used to design a matching network such as $\mathrm{L}$ matching network. The $\mathrm{L}$ matching consists of capacitor and inductor. Other matching techniques used are the quarter wave transformer, and the open and short stub matching as shown in Figure 4. These techniques are implemented using the micro-strip technology. The chosen matching network in this paper is open stub matching network.

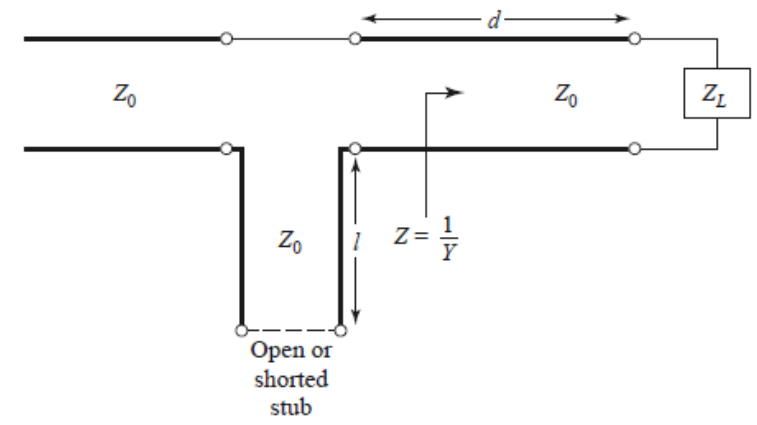

Figure 4. Series stub matching network [7]

\subsection{Schottky diode}

Schottky diode named after a German physicist Walter H. Schottky; is a semiconductor diode that have forward voltage drop and fast switching action. The normal diode has voltage drop 0.6-1.7 volts, while a schottky diode has roughly $0.15-0.45$ volts.

In this paper, Schottky diode used is the HSMS-2850 product form HP. From the spice parameter given, the value of $\mathrm{Rj}$ can be calculated using (1).

$$
R_{j}=\frac{8.33 \times 10^{-5} n T}{I_{b}+I_{S}}
$$

where: $I_{b} \quad=$ bias current

$I_{s} \quad=$ saturation current

$n \quad=$ ideality factor

$T \quad=$ temperature in Kelvin

From the spice parameter given the value of $I_{s}=1 \times 10^{-5} \mathrm{~A}, n=1.08$, and the value of $I_{b}$ is assumed to be zero because this design does not implement biasing, and the temperature is assumed to be $20^{\circ} \mathrm{C}$ which equals to $293 \mathrm{~K}$. The calculated value of $R j$ is $527 \mathrm{k} \Omega$. Schottky diode equivalent design in ADS shown in Figure 5.

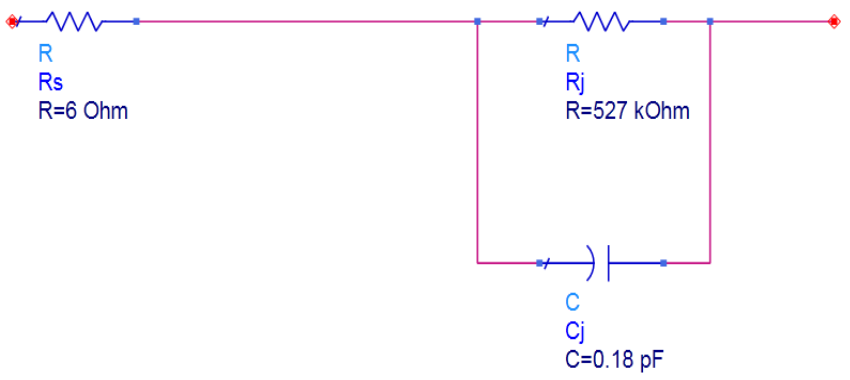

Figure 5. Schottky diode equivalent design in ADS 


\subsection{Filtering network}

The filtering network in the power detector consists of a smoothing capacitor and a load resistor connected in parallel. This forms a low pass filter that allows only the low frequency signal produced by the detector to pass through. The capacitor in the filtering network also acts as smoothing capacitor. This helps to change the input RF signal to a DC voltage. Filter network design in ADS shown in Figure 6.

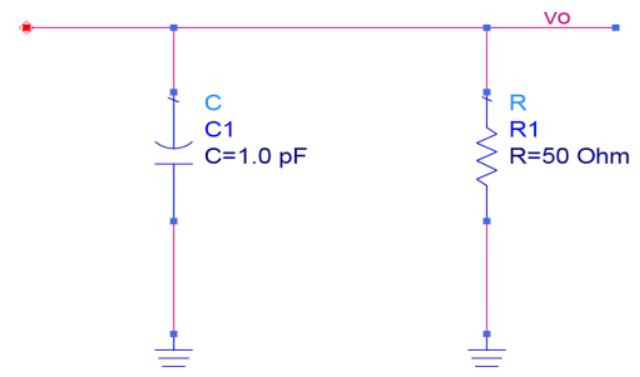

Figure 6. Filter network design in ADS

\subsection{Overall circuit simulation}

Figure 7 shows the overall design of the circuit in ADS. This circuit is used in the simulation to get the S-parameters and the VSWR. The S-parameter simulation is used to get the return loss and the insertion loss. Figure 8 is the same circuit but it is used for Harmonic Balance simulation. The Harmonic Balance simulation is used to get the output voltage versus the input power. From the designed circuit, the layout of the design is obtained using ADS. Figure 9 shows the layout of the circuit. This layout is used for the fabrication. Figure 10 shows the front side and back side of the fabricated design.

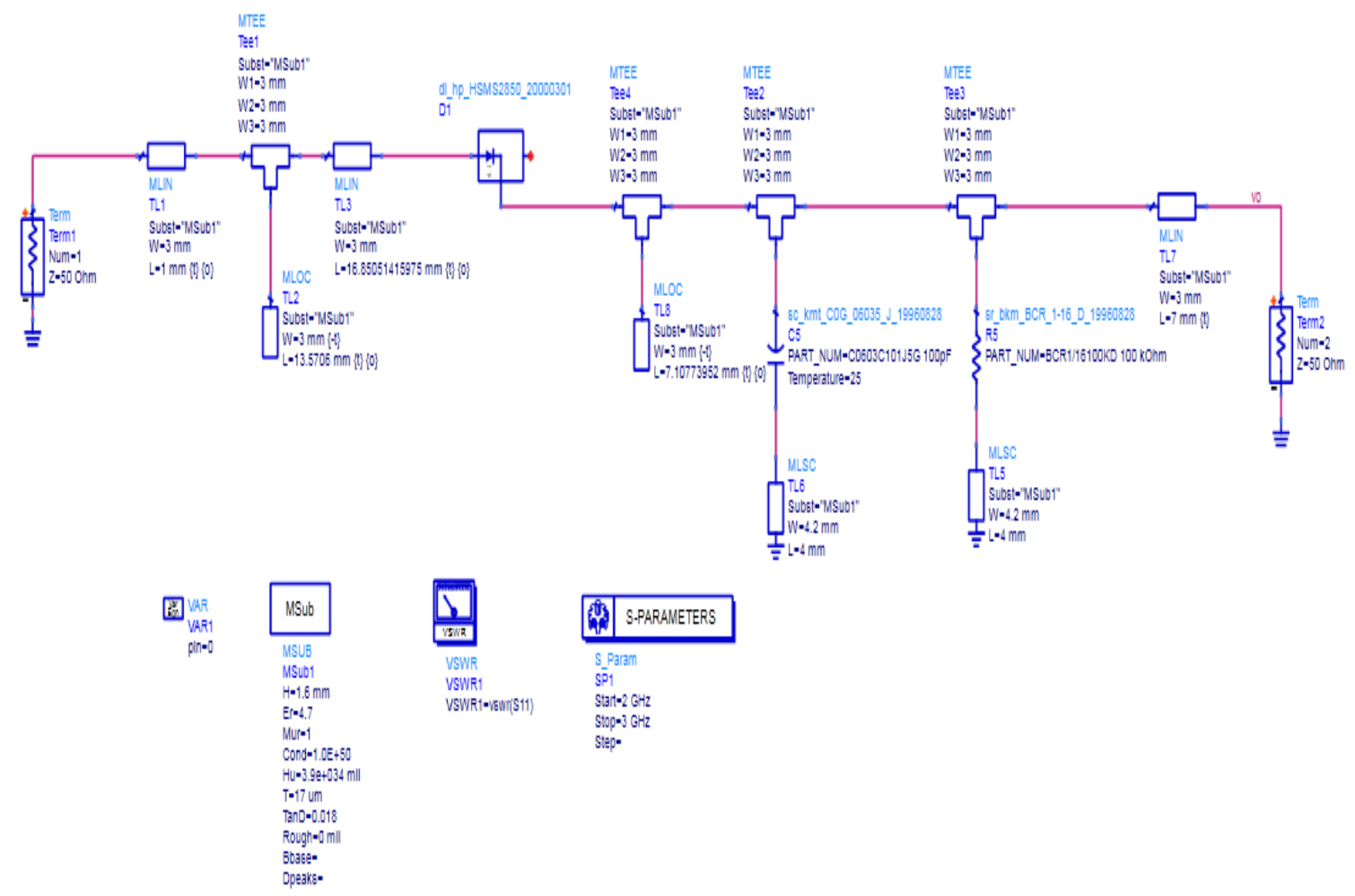

Figure 7. S-parameter simulation circuit 

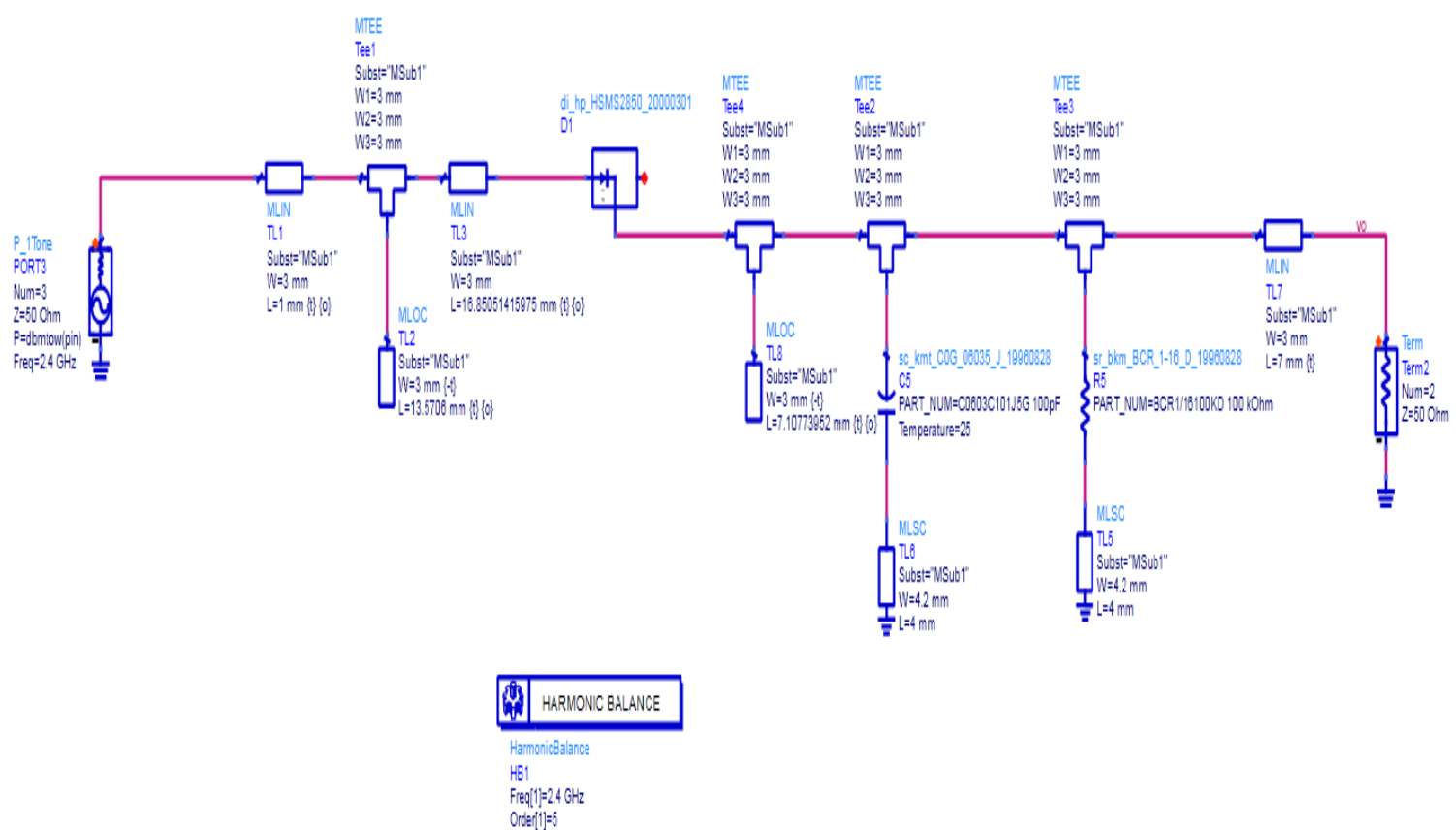

Figure 8. Harmonic balance simulation circuit

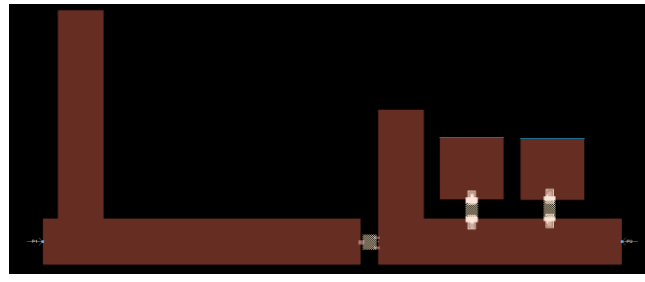

Figure 9. Design Layout

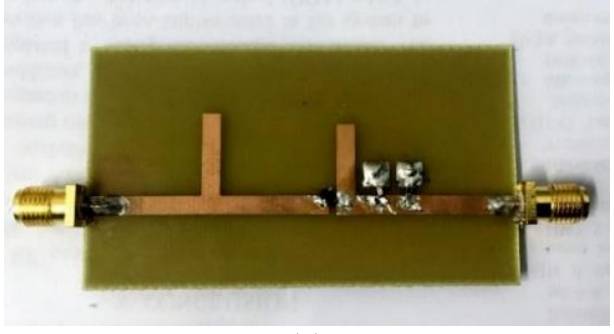

(a)

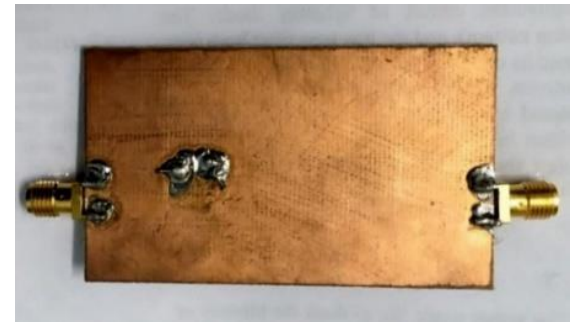

(b)

Figure 10. Fabricated circuit (a) front side, (b) back side

\section{RESULTS AND DISCUSSION}

The scattering parameters or commonly known as the S-parameters are used to provide a complete description of an N-port network. The designed circuit is two port network and the analyzed parameters are the S11, S21, and VSWR. The simulated and measured parameters are presented. The measured parameters are found using Agilent E8362B PNA network analyzer. The S11 is the measurement of how much power is reflected in port 1 , and it is commonly known as the return loss and it is measured in $\mathrm{dB}$. A good design has a return loss which is less $-10 \mathrm{~dB}$.

A comparison of the simulated and measured S11 is shown in Figure 11. The simulated S11 shows a return loss of $-35 \mathrm{~dB}$ at $2.4 \mathrm{GHz}$ compared to the measured result which gives about $-30 \mathrm{~dB}$ at the same 
frequency. This shows that there is good matching and most of the signal power passed through. Another important S-parameter is the S21 which represents the power transferred from port 1 to port 2. A circuit with good performance has an S21 which is less than $-3 \mathrm{~dB}$ at the resonant frequency.

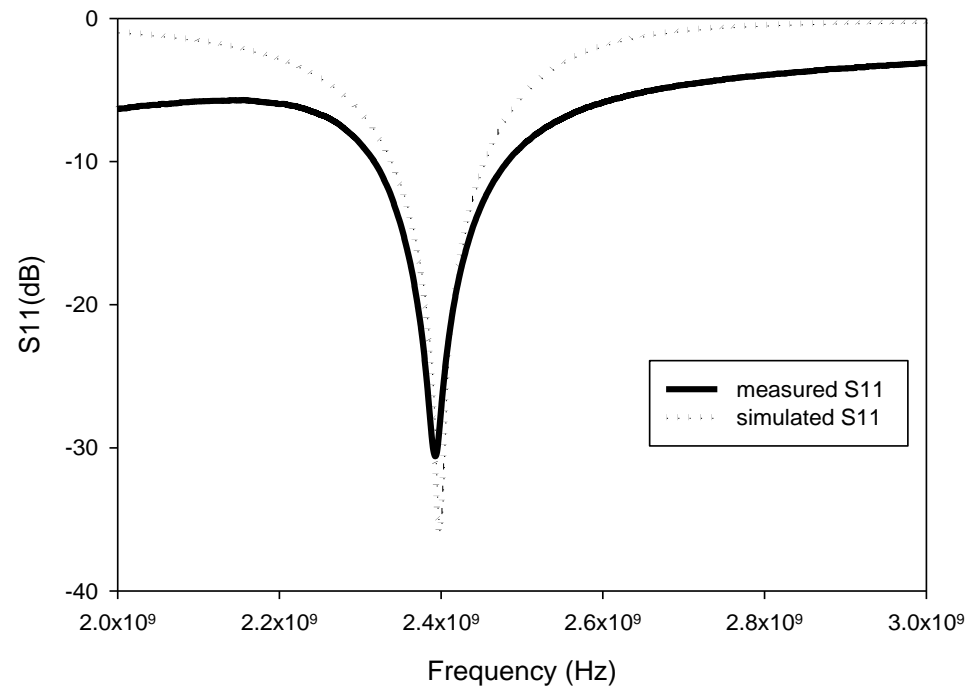

Figure 11. Measured vs Simulated S11

Figure 12 shows the simulated and measured S21, the simulated S21 at the resonant frequency is $2.5 \mathrm{~dB}$, which is in the required range, while the measured $\mathrm{S} 21$ is $-5.7 \mathrm{~dB}$ which is slightly less than the required range, this is because of the substrate which has high loss and errors from fabrication.

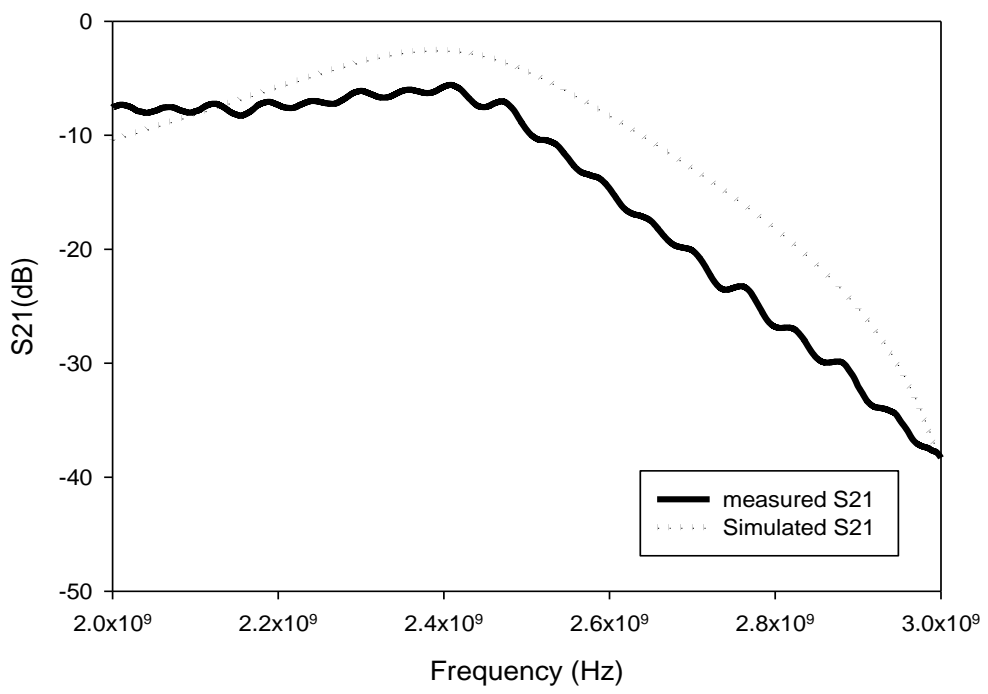

Figure 12. Measured vs simulated S21

The last parameter covered in the S-parameter simulation is the VSWR. The VSWR is another parameter used to test the impedance matching. A perfect matched circuit has a VSWR value of 1. Figure 13 shows the simulated VSWR which gives a value of 1.036 and that indicates that there is good matching. The measured result of the VSWR is also shown in Figure 13, the VSWR at the resonant frequency is 1.09 which almost the same as the simulated result. 


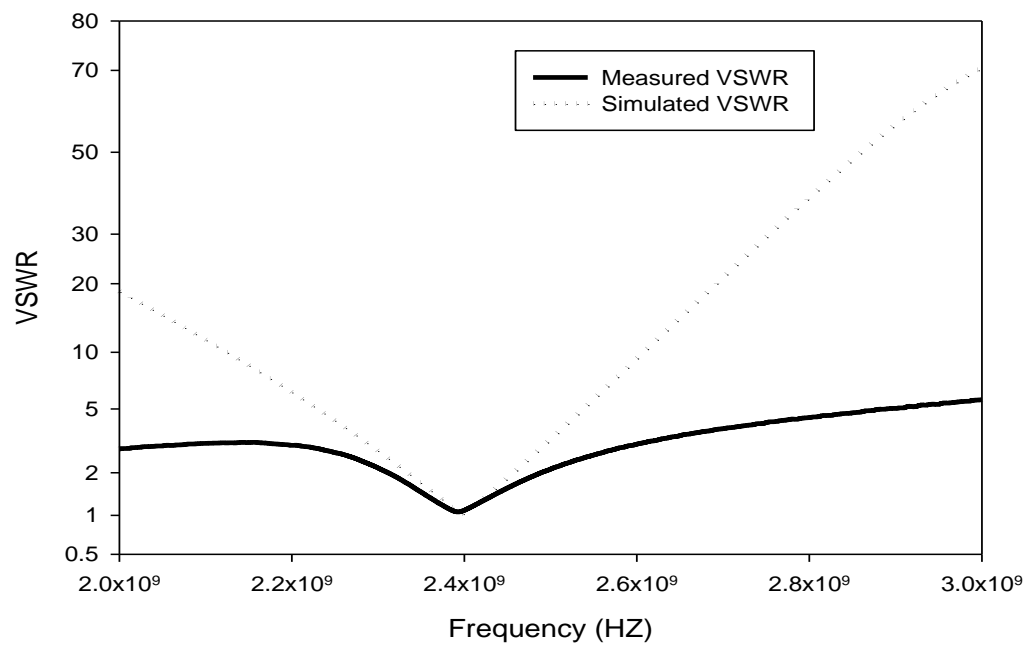

Figure 13. Measured vs simulated VSWR

Harmonic balance simulation is used to get the input power versus the output voltage. As stated before, the purpose of the power detector is to measure the power of RF signal by changing it into DC voltage. The result of the harmonic balance simulation is shown in Figure 14, clearly, it shows that as the power increases the output voltage also increases. From this result, two parameters can be obtained the first is the dynamic range which is the operating range of the detector and it is between $-10 \mathrm{dBm}$ to $-30 \mathrm{dBm}$ and the second parameter is the sensitivity of the detector which can be calculated using (1). The calculated sensitivity is found to be $40 \mathrm{mV} / \mathrm{mW}$, this means for every $1 \mathrm{~mW}$, output voltage increases by $40 \mathrm{mV}$.

$$
D_{s e n}=\frac{V_{0}(m V)}{P_{i n}(m W)}
$$

where: Dsen = Detector Sensitivity $(\mathrm{V} / \mathrm{W})$

V0 = Output Voltage $(\mathrm{mV})$

Pin $\quad=$ Input power $(\mathrm{mW})$

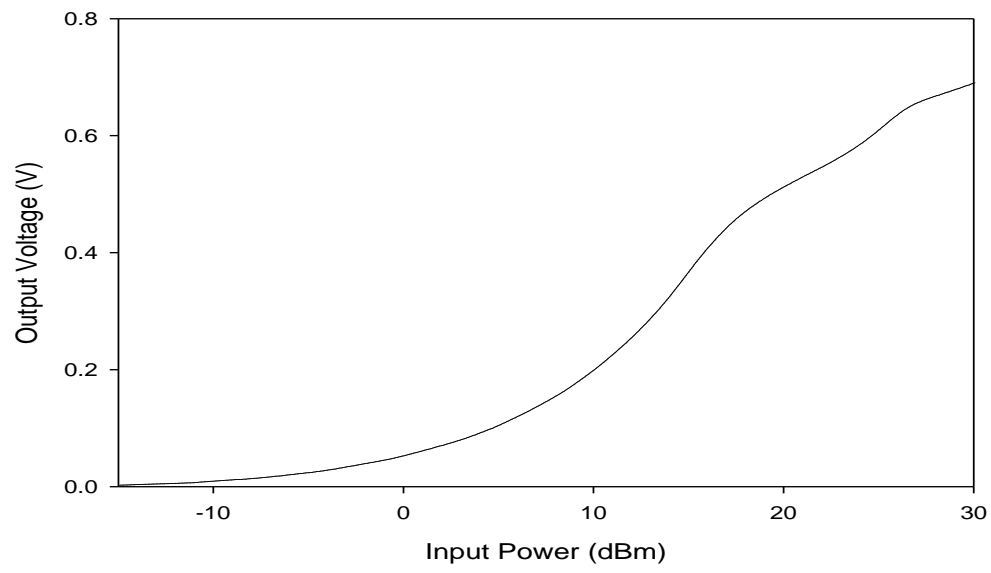

Figure 14. input power vs output voltage

\section{CONCLUSION}

RF power detector using zero biased Schottky diodes has been designed and simulated using Agilent ADS software. It has been fabricated to verify the proposed design experimentally and the S-parameters performance has good agreement between simulated and measured results. 


\section{ACKNOWLEDGEMENTS}

The author would like to acknowledge the support from the Fundamental Research Grant Scheme (FRGS) under a grant number of FRGS/1/2015/TK04/UNIMAP/02/16 from the Ministry of Higher Education Malaysia.

\section{REFERENCESs}

[1] V. Teppati, et al, "Modern RF and Microwave Measurement Techniques," pp. 108-112, 2013.

[2] B. Cimoli, et al, "An Ultra-Wideband Schottky Diode Based Envelope Detector for 2.5 Gbps signals," European Microwave Conference, EuMC, pp. 5-8, 2015.

[3] J. Liu, "Design and implementation of a broadband diode power sensor covering $0.01 \mathrm{GHz}$ to $50 \mathrm{GHz}, 2012$ Int. Conf. Microw. Millim. Wave Technol. ICMMT 2012 - Proc., vol. 1(98), pp. 349-351, 2012.

[4] S. Mann, et al, "Diode detector design for $61 \mathrm{GHz}$ substrate integrated waveguide Six-Port radar systems," 2015 IEEE Top. Conf. Wirel. Sensors Sens. Networks, WiSNet 2015, no. 1, pp. 44-46, 2015.

[5] S. Qayyum, et al, "Investigation of wideband and high sensitivity RF power detectors," Eur. Microw. Week 2014 Connect. Futur. EuMW 2014 - Conf. Proceedings; EuMC 2014 44th Eur. Microw. Conf., pp. 758-761, 2014.

[6] A. S. Zagorodny, et al, "Modeling and application of microwave detector diodes," in International Conference of Young Specialists on Micro/Nanotechnologies and Electron Devices, EDM, pp. 96-99, 2013.

[7] D. Pozar, "Microwave Engineering Fourth Edition," pp. 214-220, 2005.

\section{BIOGRAPHIES OF AUTHORS}

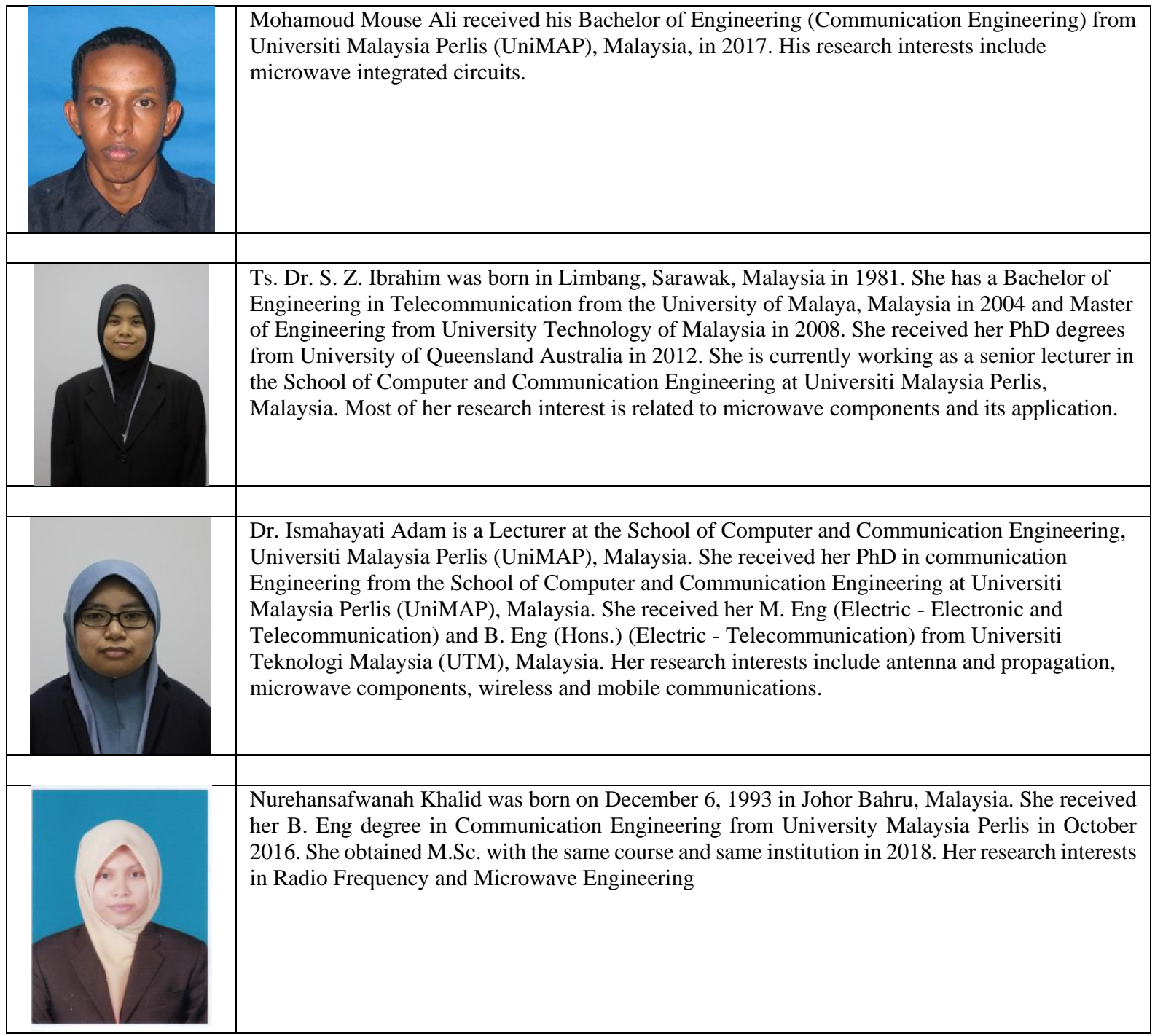

